\title{
Existence of Positive Solutions to Semipositone Fractional Differential Equations
}

\author{
Xinsheng Du \\ School of Mathematics Sciences, Qufu Normal University, Qufu, China \\ Email: duxinsheng@mail.qfnu.edu.cn
}

Received 19 June 2016; accepted 14 August 2016; published 17 August 2016

Copyright (C) 2016 by author and Scientific Research Publishing Inc.

This work is licensed under the Creative Commons Attribution International License (CC BY).

http://creativecommons.org/licenses/by/4.0/

(c) (i) Open Access

\section{Abstract}

In this paper, by means of constructing a special cone, we obtain a sufficient condition for the existence of positive solution to semipositone fractional differential equation.

\section{Keywords}

\section{Fractional Differential Equations, Boundary Value Problems, Positive Solution, Semipositone}

\section{Introduction}

The aim of this paper is to investigate the existence of positive solutions to the semipositone fractional differential equation

$$
\left\{\begin{array}{l}
D_{0^{+}}^{\alpha} u(t)+f(t, u(t))+q(t)=0, t \in(0,1), \\
u(0)=u^{\prime}(0)=u(1)=0
\end{array}\right.
$$

where $2<\alpha \leq 3, D_{0^{+}}^{\alpha}$ is the standard Riemann-Liouville fractional derivative of order $\alpha$ which is defined as follows:

$$
D_{0^{+}}^{\alpha} h(t)=\frac{1}{\Gamma(n-\alpha)}\left(\frac{\mathrm{d}}{\mathrm{d} t}\right)^{n} \int_{0}^{t}(t-s)^{n-\alpha-1} h(s) \mathrm{d} s, \quad n=[\alpha]+1,
$$

where $\Gamma$ denotes the Euler gamma function and $[\alpha]$ denotes the integer part of number $\alpha$, provided that the right side is pointwise defined on $(0, \infty)$, see [1]. Here, by a positive solution to the problem (1), we mean a function $u \in C[0,1]$, which is positive in $(0,1)$, and satisfies (1). 
Fractional differential equations have gained much importance and attention due to the fact that they have been proved to be valuable tools in the modelling of many phenomena in engineering and sciences such as physics, mechanics, economics and biology. In recent years, there exist a great deal of researches on the existence and/or uniqueness of solutions (or positive solutions) to boundary value problems for fractional-order differential equations. Sun [2] studied the existence of positive solutions for the following boundary value problems:

$$
\left\{\begin{array}{l}
D_{0^{+}}^{\alpha} u(t)+q(t) f(t, u(t))=0, t \in(0,1), \\
u(0)=u^{\prime}(0)=0, u(1)=\int_{0}^{1} g(s) u(s) \mathrm{d} s,
\end{array}\right.
$$

where $2<\alpha \leq 3, f:[0,1] \times[0,+\infty) \rightarrow[0,+\infty)$ is continuous and $f(t, 0) \neq \equiv$ on [0,1]. But paper [2] did not give the results of the existence of positive solution when the nonlinearity can take negative value, i.e. semipositone problems.

The purpose of the present paper is to apply the method of varying translation together with the fixed point theorems in cone to discuss (1) without nonnegativity imposed on the nonlinearity. Meanwhile, we also allow the nonlinearity to have many finite singularities on $t \in[0,1]$.

\section{Preliminaries and Lemmas}

In this section, we present several lemmas that are useful to the proof of our main results. For the forthcoming analysis, we need the following assumptions:

$\left(\mathrm{H}_{1}\right) \quad f:(0,1) \times[0,+\infty) \rightarrow[0,+\infty)$ is continuous. For any $t \in(0,1), f(t, 1)>0$, there exist constants $r_{1}>r_{2}>1$ such that $c^{r_{1}} f(t, u) \leq f(t, c u) \leq c^{r_{2}} f(t, u), \forall 0 \leq c \leq 1,(t, u) \in(0,1) \times[0,+\infty)$.

$\left(\mathrm{H}_{2}\right) \quad q:(0,1) \rightarrow(-\infty,+\infty)$ with $q \in L[0,1]$ and $0<\int_{0}^{1} q_{-}(s) \mathrm{d} s=R_{1}$, $0<\int_{0}^{1} G(s)\left[f(s, 1)+q_{+}(s)\right] \mathrm{d} s<\frac{L R_{1}}{\left(L R_{1}+1\right)^{r_{1}}}$, where $q_{+}(s)=\max \{q(s), 0\}, \quad q_{-}(s)=\max \{-q(s), 0\}$,

$L, G(s)$ will be defined in the following text.

In [3], the authors obtained the Green function associated with the problem (1). More precisely, the authors proved the following lemma.

Lemma 2.1 [3]. For any $h \in C[0,1]$, the unique solution of the boundary value problem

$$
\left\{\begin{array}{l}
D_{0^{+}}^{\alpha} u(t)+h(t)=0,0 \leq t \leq 1, \\
u(0)=u^{\prime}(0)=u(1)=0
\end{array}\right.
$$

is given by

$$
u(t)=\int_{0}^{1} G(t, s) h(s) \mathrm{d} s, t \in[0,1]
$$

where

$$
G(t, s)=\frac{1}{\Gamma(\alpha)}\left\{\begin{array}{lc}
t^{\alpha-1}(1-s)^{\alpha-1}-(t-s)^{\alpha-1}, & 0 \leq s \leq t \leq 1, \\
t^{\alpha-1}(1-s)^{\alpha-1}, & 0 \leq t \leq s \leq 1,
\end{array}\right.
$$

Lemma 2.2 [4]. The Green function $G(t, s)$ defined by (4) satisfies the inequality

$$
p(t) G(s) \leq G(t, s) \leq G(s), \forall t, s \in[0,1],
$$

here

$$
p(t)=\frac{(1-t) t^{\alpha-1}}{\alpha-1}, G(s)=\frac{s(1-s)^{\alpha-1}}{\Gamma(\alpha-1)}, \forall t, s \in[0,1] .
$$

Remark 2.1. A simple computation shows that there exists a constant $L>0$ such that $G(t, s) \leq L p(t), \forall t, s \in[0,1]$. 
Remark 2.2 [5]. If $f(t, u)$ satisfies $\left(\mathrm{H}_{1}\right)$, then for any $t \in(0,1), f(t, u)$ is increasing on $u \in[0,+\infty)$ and for any $\left[\eta_{1}, \eta_{2}\right] \subseteq(0,+\infty), \lim _{u \rightarrow+\infty} \min _{t \in\left[\eta_{1}, \eta_{2}\right]} \frac{f(t, u)}{u}=+\infty$.

Lemma 2.3 [6]. Let $X$ be a real Banach space, $\Omega$ be a bounded open subset of $X$ with $\theta \in \Omega$ and $A: \bar{\Omega} \cap P \rightarrow P$ is a completely continuous operator, where $P$ is a cone in $X$.

(i) Suppose that $A u \neq \lambda u, \forall u \in \partial \Omega \cap P, \lambda \geq 1$, then $i(A, \Omega \cap P, P)=1$.

(ii) Suppose that $A u \pm u, \forall u \in \partial \Omega \cap P$, then $i(A, \Omega \cap P, P)=0$.

Consider the Banach space $X=C[0,1]$ with the usual supremum norm $\|u\|=\sup _{0 \leq t \leq 1}|u(t)|$ and define the cone $P=\{x \in X: x(t) \geq p(t)\|u\|, t \in[0,1]\}$. Let $w(t)=\int_{0}^{1} G(t, s) q_{-}(s) \mathrm{d} s$, then $w(t)$ is the unique solution to (2) for $h(t)=q_{-}(t)$. Now we first consider the singular nonlinear boundary value problem

$$
\left\{\begin{array}{l}
D_{0^{+}}^{\alpha} u(t)+f\left(t,[u(t)-w(t)]^{*}\right)+q_{+}(t)=0,0 \leq t \leq 1, \\
u(0)=u^{\prime}(0)=u(1)=0,
\end{array}\right.
$$

where $[u(t)-w(t)]^{*}=\max \{u(t)-w(t), 0\}$. We have the following Lemma.

Lemma 2.4. If the singular nonlinear boundary value problem (2) has a positive solution $u(t)$ such that $u(t) \geq w(t)$ for any $t \in[0,1]$. Then boundary value problem (1) has a positive solution $v(t)=u(t)-w(t)$.

Proof. In fact, if $u$ is a positive solution to (6) such that $u(t) \geq w(t)$ for any $t \in[0,1]$. Let $v(t)=u(t)-w(t)$, then $v(t) \geq 0, t \in[0,1]$. Since $w(t)$ is the unique solution to (2) for $h(t)=q_{-}(t)$, for any $t \in[0,1]$, we have $D_{0^{+}}^{\alpha}(v(t)+w(t))+f(t, v(t))+q_{+}(t)=0$, which implies that $D_{0^{+}}^{\alpha} v(t)-q_{-}(t)+f(t, v(t))+q_{+}(t)=0$. So $D_{0^{+}}^{\alpha} v(t)+f(t, v(t))+q(t)=0$. Consequently $v(t)=u(t)-w(t)$ is positive solution to (1). This complete the proof of Lemma 2.4.

For any $u \in X$, define an operator

$$
T u(t)=\int_{0}^{1} G(t, s)\left[f\left(s,[u(s)-w(s)]^{*}\right)+q_{+}(s)\right] \mathrm{d} s, t \in[0,1] .
$$

Since for any fixed $u \in X$, we can choose $0<c<1$ such that $c\|u\|<1$. Note that $c[u(t)-w(t)]^{*} \leq c u(t) \leq c\|u\|<1$, so by $\left(\mathrm{H}_{1}\right)$, we have

$$
f\left(t,[u(t)-w(t)]^{*}\right) \leq\left(\frac{1}{c}\right)^{r_{1}} f\left(t, c[u(t)-w(t)]^{*}\right) \leq c^{r_{2}-r_{1}}\|u\|^{r_{2}} f(t, 1) .
$$

Consequently, for any $t \in[0,1]$, we have

$$
\begin{aligned}
& \int_{0}^{1} G(t, s)\left[f\left(s,[u(s)-w(s)]^{*}\right)+q_{+}(s)\right] \mathrm{d} s \\
& \leq \int_{0}^{1} G(s)\left[f\left(s,[u(s)-w(s)]^{*}\right)+q_{+}(s)\right] \mathrm{d} s \\
& \leq \int_{0}^{1} G(s)\left[c^{r_{2}-r_{1}}\|u\|^{r_{2}} f(s, 1)+q_{+}(s)\right] \mathrm{d} s \\
& \leq\left(c^{r_{2}-r_{1}}\|u\|^{r_{2}}+1\right) \int_{0}^{1} G(s)\left[f(s, 1)+q_{+}(s)\right] \mathrm{d} s .
\end{aligned}
$$

Therefore, the operator $T$ is well defined and $T: X \rightarrow X$.

Lemma 2.5. Assume that $\left(\mathrm{H}_{1}\right),\left(\mathrm{H}_{2}\right)$ hold. Then $T: P \rightarrow P$ is a completely continuous operator.

Proof. For any $u \in P$, in view of (2) we conclude that

$$
\begin{aligned}
T u(t) & =\int_{0}^{1} G(t, s)\left[f\left(s,[u(s)-w(s)]^{*}\right)+q_{+}(s)\right] \mathrm{d} s \\
& \geq p(t) \int_{0}^{1} G(s)\left[f\left(s,[u(s)-w(s)]^{*}\right)+q_{+}(s)\right] \mathrm{d} s, t \in[0,1] .
\end{aligned}
$$

Whence, it follows from (8) that $T u(t) \geq\|T u\| p(t)$, which implies $T(P) \subseteq P$. 
Next we show that $T: P \rightarrow P$ is continuous. Suppose $\left\{u_{m}\right\} \subseteq P, u_{0} \in P$, and $\lim _{m \rightarrow+\infty} u_{m}=u_{0}$. Then, there exists a constant $M>0$ such that $\left\|u_{m}\right\| \leq M, m=0,1,2, \cdots$. Since for any $t \in[0,1]$, $\left[u_{m}(s)-w(s)\right]^{*} \leq u_{m}(s) \leq\|u\| \leq M \leq M+1$, by Remark 2.2, we have

$$
\begin{aligned}
f\left(s,\left[u_{m}(s)-w(s)\right]^{*}\right)+q_{+}(s) & \leq f(s, M+1)+q_{+}(s) \\
& \leq(M+1)^{r_{1}} f(s, 1)+q_{+}(s) \\
& \leq\left[(M+1)^{r_{1}}+1\right]\left(f(s, 1)+q_{+}(s)\right) .
\end{aligned}
$$

Thus, we have

$$
\begin{aligned}
& \int_{0}^{1} G(t, s)\left[f\left(s,\left[u_{m}(s)-w(s)\right]^{*}\right)+q_{+}(s)\right] \mathrm{d} s \\
& \leq\left[(M+1)^{r_{1}}+1\right] \int_{0}^{1} G(s)\left(f(s, 1)+q_{+}(s)\right) \mathrm{d} s,
\end{aligned}
$$

and $\lim _{m \rightarrow+\infty} f\left(s,\left[u_{m}(s)-w(s)\right]^{*}\right)=f\left(s,\left[u_{0}(s)-w(s)\right]^{*}\right)$. It follows from the Lebesgue control convergence theorem that

$$
\begin{aligned}
\lim _{m \rightarrow+\infty} \mid T u_{m}-T u_{0} \| & =\sup _{t \in[0,1]}\left|T u_{m}(t)-T u_{0}(t)\right| \\
& \leq \lim _{m \rightarrow+\infty} \int_{0}^{1} G(s)\left|f\left(s,\left[u_{m}(s)-w(s)\right]^{*}\right)-f\left(s,\left[u_{0}(s)-w(s)\right]^{*}\right)\right| \mathrm{d} s \\
& =0,
\end{aligned}
$$

which implies $T: P \rightarrow P$ is continuous.

In what follows, we need to prove that $T: P \rightarrow P$ is relatively compact.

Let $D \subseteq P$ be any bounded set. Then there exists a constant $M_{1}>0$ such that $\|u\| \leq M_{1}$ for any $u \in D$. Similarly as (9), for any $u \in D, t \in[0,1]$ we have

$$
f\left(s,[u(s)-w(s)]^{*}\right)+q_{+}(s) \leq\left[\left(M_{1}+1\right)^{r_{1}}+1\right]\left(f(s, 1)+q_{+}(s)\right) .
$$

Consequently

$$
\begin{aligned}
|T u(t)| & =\int_{0}^{1} G(t, s)\left[f\left(s,[u(s)-w(s)]^{*}\right)+q_{+}(s)\right] \mathrm{d} s \\
& \leq \int_{0}^{1} G(s)\left[\left(M_{1}+1\right)^{r_{1}}+1\right]\left(f(s, 1)+q_{+}(s)\right) \mathrm{d} s \\
& \leq\left[\left(M_{1}+1\right)^{r_{1}}+1\right] \int_{0}^{1} G(s)\left(f(s, 1)+q_{+}(s)\right) \mathrm{d} s \\
& <+\infty .
\end{aligned}
$$

Therefore $T(D)$ is uniformly bounded.

Now we show that $T(D)$ is equicontinuous on $[0,1]$. For any $u \in D, t_{1}, t_{2} \in[0,1]$, by (9), (11) and the Lebesgue control convergence theorem, and noticing the continuity of $G(t, s)$, we have

$$
\begin{aligned}
\left|T u\left(t_{1}\right)-T u\left(t_{2}\right)\right| & \leq \int_{0}^{1}\left|G\left(t_{1}, s\right)-G\left(t_{2}, s\right)\right|\left[f\left(s,[u(s)-w(s)]^{*}\right)+q_{+}(s)\right] \mathrm{d} s \\
& \leq\left[\left(M_{1}+1\right)^{r_{1}}+1\right] \int_{0}^{1}\left|G\left(t_{1}, s\right)-G\left(t_{2}, s\right)\right|\left[f(s, 1)+q_{+}(s)\right] \mathrm{d} s \\
& \rightarrow 0,\left(t_{1} \rightarrow t_{2}\right) .
\end{aligned}
$$

Thus, $T(D)$ is equicontinuous on [0,1]. The Arezlà-Ascoli Theorem guarantees that $T(D)$ is relatively compact set. Therefore $T: P \rightarrow P$ is completely continuous operator.

Lemma 2.6. Let $\Omega_{1}=\left\{u \in P:\|u\|<L R_{1}\right\}$, then $i\left(T, \Omega_{1}, P\right)=1$. 
Proof. Assume that there exists $\mu \geq 1, z_{0} \in \partial \Omega_{1}$ such that $\mu z_{0}=T z_{0}$. Then $z_{0}=\frac{1}{\mu} T z_{0}$ and $0<\frac{1}{\mu} \leq 1$. Thus we have

$$
\begin{aligned}
L R_{1} & =\left\|z_{0}\right\|=\sup _{t \in[0,1]}\left|\int_{0}^{1} G(t, s)\left[f\left(s,\left[z_{0}(s)-w(s)\right]^{*}\right)+q_{+}(s) \mathrm{d} s\right]\right| \\
& \leq\left(L R_{1}+1\right)^{r_{1}} \int_{0}^{1} G(s)\left[f(s, 1)+q_{+}(s)\right] \mathrm{d} s .
\end{aligned}
$$

This contradiction shows that $i\left(T, \Omega_{1}, P\right)=1$.

Lemma 2.7. There exists a constant $R_{2}>L R_{1}$ such that $i\left(T, \Omega_{2}, P\right)=0$, where $\Omega_{2}=\left\{u \in P:\|u\|<R_{2}\right\}$.

Proof. Choose constants $\eta_{1}, \eta_{2}$ and $N$ such that

$$
\left[\eta_{1}, \eta_{2}\right] \subseteq(0,1), N>2\left[\min _{t \in\left[\eta_{1}, \eta_{2}\right]} p(t)\right]^{-2}\left[\int_{\eta_{1}}^{\eta_{2}} G(s)\right]^{-1} .
$$

From Remark (2.2), there exists $\bar{R}>2 L R_{1}$, such that

$$
f(t, u) \geq N u, t \in\left[\eta_{1}, \eta_{2}\right], u \geq \bar{R} .
$$

Let $R_{2} \geq \max \left\{\frac{2 \bar{R}}{\min _{t \in\left[\eta_{1}, \eta_{2}\right]} p(t)}, \bar{R}\right\}$. Obviously, $R_{2}>\bar{R}>2 L R_{1}$. Now we show that $u \geq T u, u \in \partial \Omega_{2}$. In fact, otherwise, there exists $y_{1} \in \partial \Omega_{2}$ such that $y_{1} \geq T y_{1}$. By (2), for any $t \in\left[\eta_{1}, \eta_{2}\right]$, we have

$$
\begin{aligned}
y_{1}(t)-w(t) & \geq y_{1}(t)-L p(t) \int_{0}^{1} q_{-}(s) \mathrm{d} s=y_{1}(t)-L p(t) R_{1} \\
& \geq y_{1}(t)-\frac{y_{1}(t)}{\left\|y_{1}\right\|} L R_{1}=y_{1}(t)-\frac{L R_{1}}{R_{2}} y_{1}(t) \\
& \geq \frac{1}{2} y_{1}(t) \geq \frac{1}{2} p(t)\left\|y_{1}(t)\right\| \geq \frac{1}{2} R_{2} \min _{t \in\left[\eta_{1}, \eta_{2}\right]} p(t) \geq \bar{R}
\end{aligned}
$$

So

$$
\begin{aligned}
R_{2} & \geq y_{1}(t) \geq T y_{1}(t)=\int_{0}^{1} G(t, s)\left[f\left(s,\left[y_{1}(s)-w(s)\right]^{*}\right)+q_{+}(s)\right] \mathrm{d} s \\
& =\int_{0}^{1} G(t, s)\left[f\left(s, y_{1}(s)-w(s)\right)+q_{+}(s)\right] \mathrm{d} s \\
& \geq \int_{\eta_{1}}^{\eta_{2}} G(t, s)\left[f\left(s, y_{1}(s)-w(s)\right)+q_{+}(s)\right] \mathrm{d} s \\
& \geq \int_{\eta_{1}}^{\eta_{2}} G(t, s) f\left(s, y_{1}(s)-w(s)\right) \mathrm{d} s \\
& \geq \int_{\eta_{1}}^{\eta_{2}} G(t, s) N\left[y_{1}(s)-w(s)\right] \mathrm{d} s \\
& \geq \frac{1}{2} N \min _{t \in\left[\eta_{1}, \eta_{2}\right]} p(t) R_{2} \int_{\eta_{1}}^{\eta_{2}} P(t) G(s) \mathrm{d} s .
\end{aligned}
$$

Consequently, $R_{2} \geq \frac{1}{2} N\left[\min _{t \in\left[\eta_{1}, \eta_{2}\right]} p(t)\right]^{2} R_{2} \int_{\eta_{1}}^{\eta_{2}} G(s)$ ds. That is $N \leq 2\left[\min _{t \in\left[\eta_{1}, \eta_{2}\right]} p(t)\right]^{-2}\left[\int_{\eta_{1}}^{\eta_{2}} G(s)\right]^{-1}$. This contradiction shows that $i\left(T, \Omega_{2}, P\right)=0$.

\section{Main Results}

Theorem 3.1. Suppose that $\left(\mathrm{H}_{1}\right)$, $\left(\mathrm{H}_{2}\right)$ hold. Then, the boundary value problems (1) has at least one positive solution $z_{0}(t)$, and exists a constant $k>0$ such that $z_{0}(t) \geq k p(t), t \in[0,1]$.

Proof of Theorem 3.1. Applying Lemma 2.6 and Lemma 2.7 and the definition of the fixed point index, we have $i\left(T, \Omega_{R_{2}} \backslash \bar{\Omega}_{R_{1}}, P\right)=-1$. Thus $T$ has a fixed point $z_{0}(t)$ in $\Omega_{R_{2}} \backslash \bar{\Omega}_{R_{1}}$ with $R_{1}<\left\|z_{0}\right\|<R$. Since $R_{1}<\left\|z_{0}\right\|$, we have 


$$
\begin{aligned}
z_{0}(t)-w(t) & \geq\left\|z_{0}\right\| p(t)-\int_{0}^{1} G(t, s) q_{-}(s) \mathrm{d} s \geq\left\|z_{0}\right\| p(t)-L p(t) \int_{0}^{1} q_{-}(s) \mathrm{d} s \\
& \geq\left(\left\|z_{0}\right\|-L R_{1}\right) p(t)=k p(t) \geq 0, t \in[0,1] .
\end{aligned}
$$

Let $y_{0}(t)=z_{0}(t)-w(t)$. It follows from Lemma (2.4) that $y_{0}(t)$ is a positive solution to boundary value problem (1), and there exists a constant $k>0$ such that $y_{0}(t) \geq k p(t), t \in[0,1]$.

\section{Acknowledgements}

We thank the Editor and the referee for their comments. This research was supported financially by the National Natural Science Foundation of China (11471187, 11571197), the Natural Science Foundation of Shandong Province of China (ZR2014AL004) and the Project of Shandong Province Higher Educational Science and Technology Program (J14LI08), the Project of Scientific and Technological of Qufu Normal University (XKJ201303).

\section{References}

[1] Podlubny, I. (1999) Fractinonal Differential Equations. In: Mathematics in Science and Engineering, Vol. 198, Academic Press, San Diego.

[2] Sun, Y.P. and Zhao, M. (2014) Positive Solutions for a Class of Fractional Differential Equations with Integral Boundary Conditions. Applied Mathematics Letters, 34, 17-21. http://dx.doi.org/10.1016/j.aml.2014.03.008

[3] Zhao, X., Chai, C. and Ge, W. (2013) Existence and Nonexistence Results for a Class of Fractional Boundary Value Problems. J. Appl. Math. Comput, 41, 17-31. http://dx.doi.org/10.1007/s12190-012-0590-8

[4] Yuan, C. (2010) Multiple Positive Solutions for (n-1,1)-Type Semipositione Conjugate Boundary Value Problems of Nonlinear Fractional Differential Equations. Electronic Journal of Qualitative Theory of Differential Equations, 36, 1-12. http://dx.doi.org/10.14232/ejqtde.2010.1.36

[5] Zhang, X.G. and Liu, L.S. (2006) Positive Solutions of Superlinear Semipositone Singular Boundary Value Problems. Journal of Mathematical Analysis and Applications, 316, 525-537. http://dx.doi.org/10.1016/j.jmaa.2005.04.081

[6] Guo, D.J. and Lakshmikantham, V. (1988) Nonlinear Problems in Abstract Cones. Academic Press, Boston.

\section{Submit or recommend next manuscript to SCIRP and we will provide best service for you:}

Accepting pre-submission inquiries through Email, Facebook, LinkedIn, Twitter, etc.

A wide selection of journals (inclusive of 9 subjects, more than 200 journals)

Providing 24-hour high-quality service

User-friendly online submission system

Fair and swift peer-review system

Efficient typesetting and proofreading procedure

Display of the result of downloads and visits, as well as the number of cited articles

Maximum dissemination of your research work

Submit your manuscript at: http://papersubmission.scirp.org/ 